\title{
EFFECTIVE EVALUATION OF CLOUD COMPUTING INVESTMENT - APPLICATION OF COST BENEFIT METHOD ANALYSIS
}

\author{
Petra Marešová, Vladimír Soběslav
}

\section{Introduction}

Dependence of economic competitiveness on ICT has been proven in the studies at enterprise level by e.g. Dedrick et al. (2003), and at macroeconomic level by e.g. Niebel (2014). All studies collectively appraise the positive influence of ICT sector development. Nowadays, employing ICT both into enterprises and state administration is a great step towards increasing productivity and therefore, economic competitiveness (Antlova et al., 2011).

Globalization and international business in the twenty-first century are mutually interconnected (Kačerauskas, 2015). The context of economic crunch unambiguously emphasizes the improvement of work performance (Mohelska \& Sokolova, 2014), companies' efficient functioning of processes, well-incurred costs as well as the ROI (Return on Investment) and undoubtedly the investments in information technologies (IT). The issue of measuring the benefits of IT investments appears the subject of the plethora of surveys carried out by various organizations. The measurement of IT benefits and IT value is considered to be one of the vital issues for senior IT management (Boardman et al., 2012; Watson et al., 1997). Although having been addressed for many years, it is still relevant in the context of new technologies in enterprises. Recent trends include cloud computing, since it shares an identically crucial problem with previous technologies: its evaluation. Therefore, several studies tackle the cloud computing investment (Dedrick et al., 2003). The final issue lies in the quantification of numerous highly qualitative variables (Svenningsen, 1998). The methods that are most commonly used for cloud computing can be divided into two categories. Economical methods by which we can obtain the output, if the cost and revenue side of cloud computing is available in monetary terms (Return on Investment (ROI), Net Present Value (NPV), the Internal Rate of Return (IRR), Economic Value Added (EVA), Total Cost of Ownership (TCO) productivity of employees) (Assuncao \& Buyya, 2009; Mei, 2008). The other group are general methods within which all the effects of the introduction of this technology are first specified, focusing on qualitative aspects of the issue and they contain financial indicators only as a minor part in themselves (Balanced Scorecard BSC, Cost Benefit Analysis (CBA), Porter Value Chain Model, Total Quality Management (TQM), Benchmarking). (Maresova, 2015)

The use of cloud computing provides companies and public institutions with many advantages (Catteddu, 2010; Sobeslav et al., 2016). Cloud computing providers, both large companies, such as Amazon, Google, or Microsoft, and small companies share the following benefits provided by cloud computing (Marks, 2010; Rittinghouse, 2010; Velte et al., 2010): budget savings and optimisation, company data accessibility from various localities, better use and expansion potential of IT infrastructure, utilization of network services and the Internet, the speed of implementation, lower number of required ICT staff, and lower ICT costs or Energy savings (Kumar, 2010).

Transfer from the current infrastructure to cloud computing is highly risky and expensive. The main question to consider about employment of cloud computing is its efficiency and asset recovery. This field has the subject of attention of many experts both on IT as well as on economy and management. Many studies dealing with the cost and savings related to cloud computing have been carried out (Kornevs et al., 2013; Özkir, 2012; Skilton, 2010; Freedson, 2011; Martens et al., 2012). For example, Jureta et al. (2009) evaluate the quality of cloud computing service from a customer's viewpoint. Kalepu et al. (2003) proposes QoS (Quality 
of Service) model for cloud computing, which puts emphasis on the metrics of distributed services. Juran, for example, has designed CWQM (Company Wide Quality Management) concept (Juran, 1999) for cloud computing, which is based on three pillars (known as Juran's trilogy): quality planning, quality control, and quality improvement. The efficiency models above have some of the following deficiencies:

- metrics are specified very generally, without the possibility of reaching specific quantitative results;

- in some studies, efficiency of only a single model of cloud computing deployment from one particular provider is described;

- the issue is not dealt with in context of indicators used by potential users;

- the issue is not dealt with in context of level of usage and perception of this technology by private and public sector in the given country.

The aim of this paper is to present the model and application for evaluation of investments into cloud computing, which allows companies to answer the basic question as to whether the migration from current IT infrastructure to cloud model is beneficial or not. The model specifies the return on investment based on given economic indicators and suitability of this solution related to the characteristics and chosen aspects of the company management.

The evaluation model will be focused on providing the infrastructure as a service (laaS - Infrastructure as a Service). Target users of this model are chiefly officers in enterprises with executive rights in investment areas. At the same time, the model will be based on the use of known enterprise economic methods and therefore it will allow for better comprehensibility and usability in practice. Removal of some problematic areas in existing evaluation methods of investment into ICT will be another asset of the model. The model will take qualitative assets and cloud computing specifics into consideration. Return on investment will be discussed in the context of indicators used in companies. Its complexity will be provided by discussing the question of suitability of cloud computing from the viewpoint of company's characteristics and activities.

\section{Methods}

The methods used to design the model were multi-criteria variant analysis, discussions with IT experts, and in-depth discussions with companies.

The multi-criteria variant analysis was used during the initial decision-making about which method on which the model would be based on to use. We used the following procedure: identification of alternatives, selection of criteria, assessing the impact of each alternative in relation to each of the criteria, determining the importance of the criteria, evaluation of alternatives. In this case, to determine the importance of the criteria, and possibly also the selection of the criteria involved an expert group. Some of them were addressed through questionnaires sent to them to comment on the criteria and their importance. Criteria (K1-K6) are determined with regard to the needs of business sector in the Europe and they are based on the nature of the benefits of cloud computing. To determine the importance of the criteria for the selection of a method for assessing the benefits of knowledge management, the method of allocation of 100 points was chosen - the so-called Metfessel allocation. The actual calculation is implemented using MS Excel program for manual implementation of the scoring method and calculation tool Multi Criterion Analysis (MCA) Kosa for the method of linear partial utility functions (weighted sum), TOPSIS and ELECTRE I, AGREPREF, MAPPAC and PROMETHE (Maresova, 2016).

The analysis was carried out during the period from October to December 2014. The initial CBA CC (Cost benefit analysis for cloud computing) model was assembled in January 2015. It was based on the analysis of documents describing CBA usage and aimed at evaluation of investments into IT, and on the results from qualitative and quantitative survey of cloud computing state in Czech enterprises (Marešová et al., 2014).

Discussions with IT experts (7) were carried out with the aim to design the structure of the evaluation model of cloud computing that would correspond with the characteristics of this technology, furthermore to ensure the functionality of the model related to the technical parameters of cloud computing. Another aim was to verify that the selected indicators and metrics are suitable. Of course, it was taken into consideration whether or not it is applicable in business practice. The discussions were carried out during the period from January to March 2015. 
Feedback on clarity and structure of entries identifying the current state of IT in the company and required level of cloud computing from the company IT experts was carried out consequently. This was executed by the in-depth talks with the companies, some of which had already employed cloud computing (12), and some were considering it (7). The discussions were realised in cooperation with NMS Research form. The aim of the discussions was both to verify the suggested model of cloud computing effectiveness and to address the completeness of the entries. Furthermore, the queries addressed arguments for the deployment, migration process, satisfaction with the current state, expenses, and problems. All of that with purpose to verify the correctness of suggested entries of expenses and assets in CBA, which could be translated to numbers in the following steps. The target group were head workers in IT departments in chiefly medium-sized companies. The discussions were carried out during the period from 3 June to 25 June 2015.

Afterwards, the model was modified, tested, and described in several case studies in the period from $1^{\text {st }}$ August to $30^{\text {th }}$ November 2015.

After the CBA CC model was finished, it was possible to proceed to program an application that would automatically calculate economical return on investment and generate reports on the suitability of investing into cloud computing. This process was methodically separated into three basic steps. First of all, it was necessary to choose suitable platform, programming language, and service distribution method (full application, web pages, or mobile app).

As the most suitable method, robust JAVAbased platform and the model of primary service distribution via web pages were chosen, which would allow expanding service distribution model nearly in any way in the future, including the connection to external systems. Afterwards, the economic model had to be converted into algorithmic model, which was the first step in automating the whole process. The last step was to create a use-case and a data model. Based on them, an application was created and testing was commenced. The web application is being developed since $1^{\text {st }}$ February 2016, and its functionality is currently being tested. This procedure is depicted in Fig. 1.

- Transformation of qualitative and quantitative parameters.

\section{Results}

Model development consisted of two main steps. First, the specification of the steps within the framework of CBA adjusted to cloud computing specificities was performed. Therefore, a new theoretical CBA CC model was created (Marešová \& Klímová, 2015). The second step was to specifically develop the model to directly allow automatic economic indicator calculations.

\section{Fig. 1: Methodical procedure}

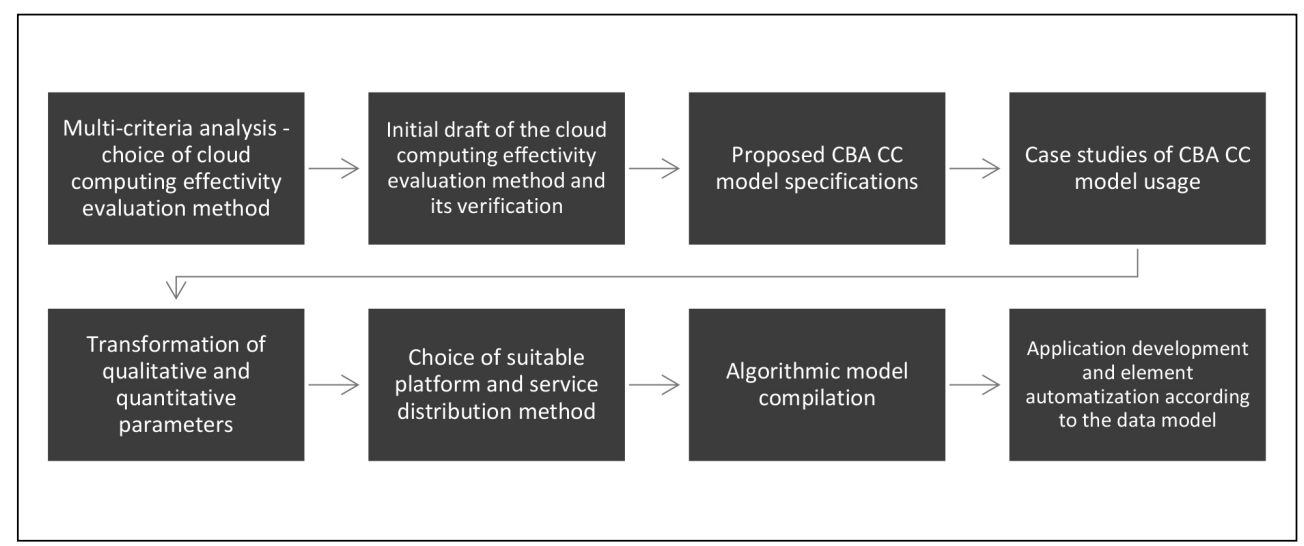




\subsection{Theoretical Model - Cost Benefit Analysis for Cloud Computing (CBA CC)}

Theoretical cloud computing investment evaluation model is based on the CBA method (Marešová et al., 2016). Asset and expense are the key terms in this model and after being converted to quantitative format they are compared (Nas, 1996). Economic markers and sensitivity analysis are its outcome. Specific steps of the theoretical CBA CC model are as follows (Marešová \& Klímova, 2015):

1. CC utilization criteria specifications,

2. current state and required services characteristics,

3. decision about what subjects are impacted by the project,

4. determination and potential quantification of all relevant expenses and assets,

5. stating all the consequences of CC deployment in financial units,

6. criteria indicators calculation,

7. sensitivity analysis and project evaluation.

\subsection{Application Model - Cost Benefit Analysis for Cloud Computing (CBA CC)}

The proposed economic model allows gathering two basic types of output for the information about suitability of investment into cloud computing. The first output type informs about the cost based on the information about the current and the required IT state. The second output type is a complex report on the suitability of the cloud computing deployment in the company based on further additional information.

Input information that has to be known about the company is divided into three areas:

- Business characteristics;
- Strategic management;

- Technical parameters.

Parameters related to the enterprise characteristics can set direction of the initial consideration about employment of cloud model. There are organisation types that are not suitable for the transfer for their nature and data gathering character and vice versa. Advantages and disadvantaged related to the organisation character will be described in the final report. Indicators of the strategic company management allow ascertaining assets and risks of cloud model employment in more detail. The final value of investment effectiveness will be commented on in relation to these parameters. Technical parameters represent particular requirements of the infrastructure being employed and take into consideration the extent of investments necessary to set up the information infrastructure inside the company.

For the complex report it is necessary to know the information about all of the areas. To determine the expenses, Technical parameters will suffice. Economic model generally follows two parameter types: qualitative parameters such as characteristics of the company, enterprise, business processes, or strategic management in the company, and quantitative parameters such as technical requirements of cloud computing. Sorting out particular variables is essential for the model, and it is assumed that to automatize the calculations of economic assets and to be able to state them in particular currency, it is substantial to choose the variables that have the maximum direct impact on the matter. Otherwise, the model would work with a high rate of uncertainty. Qualitative parameters cannot be determined; their relation to the calculation itself is indistinct or indirect. Despite the stated disadvantages, they can, although with certain amount of uncertainty,

Tab. 1: General output generation model

\begin{tabular}{l|l|l|l} 
& \multicolumn{1}{|c|}{ Type } & \multicolumn{1}{c|}{ Value } & \multicolumn{1}{c}{ Multiplier } \\
\hline $\begin{array}{l}\text { Monitored } \\
\text { parameter }\end{array}$ & Qualitative & $\begin{array}{l}\text { Individual scale, related } \\
\text { to the parameter }\end{array}$ & $\begin{array}{l}1-3 \text { attributed } \\
\text { to the model author }\end{array}$ \\
\hline & Quantitative & $\begin{array}{l}\text { Specific numeral value given } \\
\text { by the user }\end{array}$ & $\mathrm{X}$ \\
\hline
\end{tabular}


provide a complementary answer as to whether the migration to cloud computing is suitable or not. An example of such a variable is such an enterprise where agriculture, utilisation and effectiveness of cloud computing can be expected to be lower than in E-commerce, for instance. In the tables below, specific areas are shown and variables are briefly described. Tab. 1 specifies general principle of result evaluation. According to the sum of assigned multipliers, outcomes of the quantitative variables point at one of the three commented outputs for those potentially interested in cloud computing, which will be generated.

Tab. 2 presents first of the three areas of the parameters being monitored. All of the variables here are qualitative, they are not expressed in numbers and from the viewpoint of the output they will point at one of the three variants of commented reports, in which there will be recommendations about suitability of the transfer to CC. For instance, in Geographical spread of the company and Fluctuation of the orders during the year, high percentage of orders online points out more to the recommendation to transfer to CC. From the perspective of the geographical spread of the company it is necessary to address the question of legislative conditions of data storing and safety, where there are differences between the United States and Europe, for instance. All of this is discussed in the final report to the companies.

\section{Tab. 2: Business characteristics}

\begin{tabular}{l|c}
\multicolumn{1}{c|}{ Input information/query } & Value \\
\hline Line of business & CZ NACE \\
\hline Commercial relationship type & B2B/B2C/B2G \\
\hline How many employees utilized remote access to data & Number \\
\hline Geographical spread of the company & CzR/Europe/worldwide \\
\hline Fluctuation of the order during the year & $\%$ \\
\hline $\begin{array}{l}\text { Percentage of orders made online } \\
\text { How many employees would benefit from transfer to cloud environment in } \\
\text { one of the following ways? Mobility support, remote access, management } \\
\text { savings, i.e. lowering the difficulty of passing processes and management } \\
\text { of the infrastructure outside of the enterprise }\end{array}$ & Hours per month \\
\hline
\end{tabular}

The second specified area is the strategic management of the company (Tab. 3). The queries are designed to ascertain how employees are occupied by IT administration, quality of current and required services, or at how difficult the transfer to new technology would be for the company. The query about data transfer to the third party is important too as it can be limiting for cloud computing utilization, in particular for laaS model. In case of large amount of data, private cloud should be preferred, and transfer to laaS model can be recommended only for the leftover data.

Another important variable with relatively high impact on the results of the model is required availability of the service/infrastructure, and SLA (Service Level Agreement) respectively (Horalek et al., 2014). SLA defines the level of the service required by the customer, which requires a corresponding technical solution. In general, it is possible to state that the higher the level of SLA, the more expensive is the technology to attain it (Nie \& Chen, 2012). Availability of 99.999 percent requires infrastructure that has been designed for daily blackouts in seconds. In such an infrastructure it is possible, unlike in a typical one with common availability, to shut down one of the servers without limiting the customer working with e.g. ERP system. Cloud computing infrastructure generally anticipates traffic in data centre, which meets the strictest security operating rules, and in addition to it is geographically replicated to other places. If this level is not required, final result is significantly influenced making the classic infrastructure more favourable. 


\begin{tabular}{|c|c|}
\hline Input information/query & Value \\
\hline How much data cannot be transferred to the third party? & $\%$ \\
\hline $\begin{array}{l}\text { Can your IT adapt to your company growth, especially in terms of } \\
\text { requirements to store continuously growing amount of data and greater } \\
\text { computing requirements? }\end{array}$ & Yes/no \\
\hline What is the renewal cycle in years? & Number of years \\
\hline $\begin{array}{l}\text { Amount of expenses connected to current infrastructure administration / } \\
\text { savings at IT employees/year }\end{array}$ & EUR \\
\hline Number of employees & Number \\
\hline Number of hours per employee & Hours \\
\hline Hourly rate & EUR/hour \\
\hline Other expenses saved & EUR \\
\hline $\begin{array}{l}\text { Amount of expenses connected to employee training during the transfer } \\
\text { to cloud model and loss of profit caused by the transfer }\end{array}$ & EUR \\
\hline Other expenses for training & Sum \\
\hline What is the average loss per hour when the technology is unavailable & EUR \\
\hline $\begin{array}{l}\text { Estimated loss of the company caused by the infrastructure unavailability } \\
\text { per hour }\end{array}$ & EUR \\
\hline What is current infrastructure/SLA availability rate? & $\%$ \\
\hline Unavailability in hours/year & Number of hours \\
\hline Availability of cloud infrastructure (AZURE) & $\%$ \\
\hline $\begin{array}{l}\text { Operating expenses for current infrastructure without personal expenses } \\
\text { per year (buildings, energies...) variables: currency }\end{array}$ & EUR \\
\hline Amount of investment into current infrastructure & EUR \\
\hline Amount of investment into licenses per year & EUR \\
\hline Amount of investment into product support & EUR \\
\hline Investment into security systems (processing, information, physical) & EUR \\
\hline
\end{tabular}

The technical parameters in Tab. 4 represent specific parameters of the procured architecture and take into consideration amount of investment necessary to ensure operation of the information infrastructure inside the enterprise. It is important to be aware that cloud computing and current infrastructure represent different models from the viewpoint of operating funding. Cloud computing is, to a certain extent, hired service with high flexibility for changes at the level of current requirements of the company. On the other hand, classic infrastructure employment is a blend of investment and operating expenses, which include e.g. direct and indirect personal expenses, energies, insurances, building security, rental, purchases of HW, SW, manufacturers' support etc. This blend is very individual for particular companies and therefore it is impossible to incorporate it into single economic model. Because of this, IT operation is divided into common areas with the requirement of stating amount of expenses that is in average spent by individual departments per year. Length of the investment cycle is given specifically by the particular organisation as well and it is possible to articulate it in the model. Through this it has been achieved that the CBA CC model is capable of comparing the effectiveness of cloud and classic infrastructures, i.e. compares what can be compared. 


\section{Tab. 4: Technical parameters}

\begin{tabular}{l|c}
\multicolumn{1}{c|}{ Input information/query } & Value \\
\hline $\begin{array}{l}\text { Overall expenses for instances/servers in the cloud per year } \\
\text { (currently according to AZURE CALCULATOR) }\end{array}$ & Sum \\
\hline Type of instances/virtual servers & Type \\
\hline Number of instances/virtual servers & Number \\
\hline Expenses per instance/year & EUR \\
\hline Overall expenses for backing up & EUR \\
\hline Requirements for the backup system capacity in GB (max. 500 GB) & GB \\
\hline Expenses per instance & EUR \\
\hline Number of protected instances (servers for backing up) & Number \\
\hline Overall expenses for networks & EUR \\
\hline Amount of data transferred from cloud/data centres in TB/year & TB \\
\hline Expenses for data transfers from cloud/data centres & EUR \\
\hline Number of public IP addresses for instances (not time-restricted) & Number \\
\hline Expenses for public IP addresses & EUR \\
\hline Overall expenses for cloud storage (not time-restricted) & EUR \\
\hline Requirements for cloud storage capacity in GB & GB \\
\hline Requirements for other services/administration/reporting per year & EUR \\
\hline
\end{tabular}

Source: own

The model provides two output types. One is information on the expenses based solely on values from Tab. 4. However, the main advantage of the model lies in evaluation of the suitability of $\mathrm{CC}$ employment. A detailed report is generated based on the input. It describes the overall expenses for cloud computing and calculations of the following economic indicators: Return on investment (ROI), Total cost of ownership (TCO), and Net present value (NPV). Sensitivity analysis is performed for the indicators, where all the input parameters are altered $(+/-10 \%)$ and results recalculated. Evaluation is performed in the context of company characteristics, way of organisation management, employees' behaviour, or kind of business relationship.

\subsection{Technical Solution of CBA CC Calculator's Operation}

Technical solution of web application capable of calculating CBA CC has been designed to be operable and to ensure that the requirements on these systems are met. Scalability, elasticity, and mobility of the whole solution are the principal ones of these requirements. The platforms used for the design are JAVA and WildFly 10 with connection to PostgreSQL 9.x database. WildFly, previously known as JBoss, is an application server authored by JBoss. WildFly is written in Java, and implements the Java Platform, Enterprise Edition (Java EE) specification. WildFly is free and open-source software which supports multiple platforms. Data can be saved into other databases or formats, such as Open Source JAVA application server. Fundamental overview of application infrastructure is described on the following picture (Fig. 2).

Another, yet important issues are security and ethical aspects due to the data sensitivity, confidentiality and law or other policies limitations. Transport Layer Security (TLS) utilizing certificates from trustworthy certification authorities is used to provide safety measures. Its application is accommodated to Enterprise Edition 7 standards. The image below the diagram introduces the basic architecture of the system designed (Fig. 2). In the case of higher load when a user accesses particular node, the 


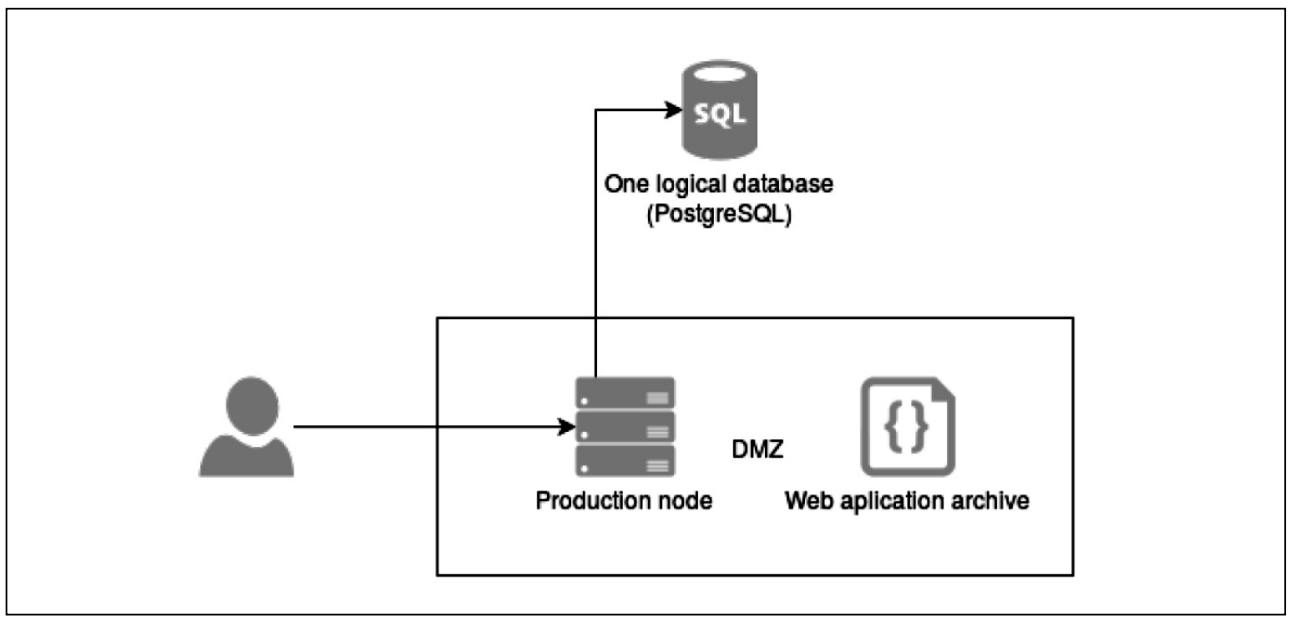

Source: own

load is redistributed among multiple computing nodes. PostgreSQL database and application archive provides a connection to the internal logic of the production node.

\section{Conclusions and Discussion}

Today's business environment is characteristic by ever-growing necessity of effective use of all available resources and by focusing on the processes that add value to the enterprise and their quality evaluation (Kozel \& Mohelská, 2010; Marston, 2011; Molnár \& Střelka, 2012; Voříšek et al., 2015). Technology that can contribute to these goals is cloud computing. Its deployment in the Czech Republic and in the countries of the European Union is, despite favourable predictions, rather low and its growth is still slow. The main barrier is the lack of companies' needs to change their information technologies and difficulties to formulate assets and savings that can be achieved by the technology (Marešová \& Hálek, 2015). The CBA CC method can be used online and in the context of specifics of given company's management. This allows complex asset formulation and extends existing set of methods usable to evaluate investments into IT. Assets of the CBA CC method compared to commonly used methods in IT are:

- complexity,

- options of using both static and dynamic methods,
- adjustment to enterprise characteristics and its activities,

- it allows conversion of qualitative variables to quantitative ones,

- as opposed to methods used directly for investments into IT, it is known better and used more in the Czech business environment, since it can clarify the suitability of the given investment.

Its main difference and advantage compared to the original Cost Benefit Analysis method lies in these areas:

- change of number and structure of steps in CBA to correspond to cloud computing employment,

- individual content of first three steps of the method corresponds to the incentives of cloud computing employment,

- new list of criteria queries for decisionmaking regarding cloud computing,

- scheme has been devised to specify entries of the current and desired IT state,

- structure of the subjects that can be influenced by the technology employment has been created,

- in terms of criteria indicators' calculation, attention is paid to those that correspond to the usage in Czech environment and at the same time are used in cloud computing. 
The main advantage of proposed application, in comparison with other existing applications, is the use of advanced economical evaluation models. This approach provides interesting possibilities in comparison to other methods used for evaluation of corporate assets or IT infrastructure. On the Internet, there can be found basic calculators which presents products in marketing way and simply count the final price. These applications usually multiply the number of CPU, RAM and other hardware, software and consequent parameters and provide direct sellers of cloud computing services (e.g. Microsoft Azure, Amazon, Rackspace, etc.). Another, yet important difference compared to other basic calculators, is greater objectivity and comprehensiveness the developed application is provider/vendor independent and it is based on the following main principles.

- Requirement of inputs that take into account the specifics of companies both in relation to the field of business, IT requirements, strategic management, not only the hardware requirements for the data transfer etc.

- Scalability and complexity is provided by a wider range of output (traditionally referred to as ROI or TCO) in the form of static and dynamic economic indicators known in the corporate environment.

- Includes sensitivity analysis and thus enables recalculate the result and based on a certain \% change of input parameters.

Usage of CBA CC method bears certain dangers. From the perspective of the method itself, the quality of the analysis is very high when following the basic rules and executed properly. However, problems related to technical limits can occur such as insufficient input data, problematic availability of methods suitable for converting the impact of the effects to financial flows etc. This problem is also connected to setting the discount rate. The discount rate can significantly influence the calculation and value of e.g. NPV or of other criteria. Therefore, it is essential to pay maximum attention to setting this interest rate. The factor that can distort CBA's results is in case of cloud computing quick change of IT prices. In recent years, significant decrease in prices of IT and quick rise of new technologies can be observed. In case of NPV calculation for 10-year horizon, this can have a great impact. Incorporating expected price development in ICT sector would mean to predict this development and include it into the calculation by e.g. modifying the discount rate. Another factor of great significance when compiling CBA are its authors. It is desirable that persons specifying the project's impact be familiar with not only IT requirements of the company, but also its management.

From the perspective of the online use of the method, currently the model has been finalised and the application developed; furthermore, technical testing of the system and the verification of the model in selected companies is in progress. Based on the testing results, the model will be finished and released for commercial use. Another challenge in this area is the production of a portal that would be capable of automatically implementing new models and variables which could define their mutual relationships. From the technical and user viewpoint, the model is currently static and is dedicated to solve only one problem to evaluate the expenses for migration from the traditional infrastructure to the cloud one. In the next phase, we expect interconnection with other projects, such as measuring the performance of cloud services and the development of enhanced independent dynamic model. The dynamic model would allow the handling of various independent project kinds in fact not connected to the model, such as investments into medication or production technologies, or use wide range of economic methods.

This research was supported by the following projects TACR "Applications for the economic evaluation of the migration of IT infrastructure into the cloud" no. TG0 2010020, project of scientific excellence and the project of internal specific research (University of Hradec Kralove, Faculty of Informatics and Management). Furthermore, we would like to thank Ruzena Štemberková for help in getting feedback from companies.

\section{References}

Assuncao, M. D., \& Buyya, R. (2009). Evaluating the costbenefit of using cloud computing to extend the capacity of clusters. In Proceedings of the 18th ACM international symposium on High performance distributed computing (pp. 141-150).

Boardman, A. E., Greenberg, D. H., Vining, A. R. et al. (2006). Cost-benefit analysis: 
concepts and Practice (3rd ed.). Upper Saddle River, NJ: Prentice Hall.

Buyya, R., Yeo, C. S., Venugopal, S., Broberg, J., \& Brandic, I. (2009). Cloud computing and emerging IT platforms: vision, hype, and reality for delivering computing as the 5th utility. Journal on Future Generation Computer Systems, 25(6), 599-616. doi:10.1016/j.future.2008.12.001.

Dedrick, J., Gurbaxani, V., \& Kraemer, K. L. (2003). Information technology and economic performance: a critical review of the empirical evidence. Computing Surveys, 35(1), 1-28. doi:10.1145/641865.641866.

Freedson, P. S., Lyden, K., Kozey-Keadle, S., \& Staudenmayer, J. (2011). Evaluation of artificial neural network algorithms for predicting METs and activity type from accelerometer data: Validation on an independent sample. J. Appl. Physiol., 111(6), 1804-1812. doi:10.1152/ japplphysiol.00309.2011.

Gartner. (2016). Gartner Predict Cloud Computing Spending to Increase by $100 \%$ in 2016. In Says AppsCare. Retrieved September 8, 2016, from http://www.prweb.com/ releases/2012/7/prweb9711167.htm.

Horalek, J., Sobeslav, V., \& Pavlik, J. (2014). Statistic and analysis of service availability in cloud computing. In IDEAS'14 (pp. 310-313). Porto: Byte Press.

Juran, J. (1999). Juran's Quality Handbook (5th ed.). New York: McGraw-Hill.

Jureta, I. et al. (2009). A comprehensive quality model for service-oriented systems. Software Qual. Journal, 17(1), 65-98. doi:10.1007/s11219-008-9059-2.

Kačerauskas, T. (2015). Technologies in creative economy and creative society. Technological and Economic Development of Economy, 21(6), 855-868. doi:10.3846/202949 13.2015.1036325.

Kalepu, S., Krishnaswamy, S., \& Loke, S. W. (2003). Verity: a QoS metric for selecting Web services and providers. Web Information Systems Engineering Workshops, 131-139. doi:10.1109/WISEW.2003.1286795.

Kornevs, M., Minkevica, V., \& Holm, M. (2013). Cloud computing evaluation based on financial metrics. Information Technology and Management Science, 15(1), 87-92. doi:10.2478/v10313-012-0013-8.

Kozel, T., \& Mohelská, H. (2010). Modely firem $\mathrm{s}$ mobilně orientovanou architekturou. E\&M Ekonomie a Management, 13(4), 135-142.
Kumar, K., Lu, Y. (2010). Cloud computing for mobile users: can offloading computation save energy. IEEE Computer Society, 43(4). doi:10.1109/MC.2010.98.

Mei, L. (2008). A tale of clouds: Paradigm comparisons and some thoughts on research issues. Asia-Pacific Services Computing Conference, 2008. APSCC '08 (pp. 464-469). Washington D.C.: IEEE. doi:10.1109/ APSCC.2008.168.

Maresova, P., \& Halek, V. (2015). Deployment of Cloud Computing in Small and Medium Sized Enterprises in The Czech Republic. E\&M Ekonomie a Management, 17(4), 159-173. doi:10.15240/tul/001/2014-4-012.

Maresova, P., \& Klimova, B. (2015). Investment Evaluation of Cloud Computing in the European Business Sector. Applied Economics, 47(36), 3907-3920. doi:10.1080/0 0036846.2015 .1019041$.

Marešová, P., Soběslav, V., \& Krejcar, K. (2016). Cost Benefit Analysis - Evaluation Model of Cloud Computing Deployment for Use in Companies. Applied Economics, 49(6), 521-533. doi:10.1080/00036846.2016.1200188.

Marks, E. A., \& Lozano, B. (2010). Executive's Guide to Cloud Computing. New Jersey: John Wiley \& Sons: Inc.

Marston, S., Bandyopadhyay, S., Zhang, A., \& Ghalsasi, A. (2011). Cloud Computing - The business perspective. Decision Support Systems, 51(1), 176-189. doi:10.1016/j.dss.2010.12.006.

Martens, B., Walterbusch, M., \& Teuteberg, F. (2012). Costing of Cloud Computing Services: A Total Cost of Ownership Approach. In Proceedings of the 45th Hawaii International Conference on System Sciences (pp. 1563-1572). Maui, Hawaii.

Mell, P., \& Grance, T. (2009). The NIST Definition of Cloud Computing. National Institute of Standards and Technology, Information Technology Laboratory. Retrieved from https:// www.nist.gov/sites/default/files/documents/itl/ cloud/cloud-def-v15.pdf.

Mohelska, H., \& Sokolova, M. (2014). Effectiveness of using e-learning for business disciplines: the case of introductory management course. E\&M Ekonomie a Management, 17(1), 82-92. doi:10.15240/tul/001/2014-1-007.

Molnár, Z., \& Střelka, J. (2012). Competitive intelligence $\mathrm{v}$ malých a středních podnicích. E\&M Ekonomie a Management, 15(3), 156-170. 
Nas, T. F. (1996). Cost-Benefit Analysis. Theory and Application. Thousand Oaks, CA: SAGE Publications.

Nie, G., Xueni, E., \& Chen, D. (2012). Research on Service Level Agreement in Cloud Computing. In Advances in Electric and Electronics (pp. 39-43). Berlin, Heidelberg: Springer.

Niebel, T. (2014). ICT and Economic Growth - Comparing Developing, Emerging and Developed Countries ZEW [Centre for European Economic Research Discussion Paper No. 14-117]. doi:10.2139/ssrn.2560771.

Özkir, S. B. (2012). Analysis of SaaS and On Premise ICT solutions for SMEs in Turkey. Graduate School of Social Sciences Department of Business Administration. Retrieved from: https://pdfs.semanticscholar.org/fdff/ 387bbc0da9229f4c0d44354b9fa1b3f0861e.pdf.

Rittinghouse, J. W., \& Ransome, J. F. (2005). Business continuity and disaster recovery for infosec managers. Boston: Elsevier.

Skilton, M. (2010). Building Return on Investment from Cloud Computing. The Open Group. Retreived from http://www.opengroup. org/cloud//whitepapers/ccroi/index.htm.

Sobeslav, V., Maresova, P., Krejcar, O., Franca, T. C., \& Kuca, K. (2016). Use of cloud computing in biomedicine. J Biomol Struct Dyn, 34(12), 2688-2697. doi:10.1080/07391102.201 5.1127182 .
Svenningsen, K. (1998). An evaluation model for electronic resources utilizing cost analysis. The Bottom Line, 11(1), 18-23. doi:10.1108/08880459810369209.

Velte, A. T., Velte, T. J., \& Elsenpeter, R. (2010). Cloud Computing: A Practical Approach. McGraw-Hill Companies.

Vořišek, J., Pour, J., \& Buchalcevová, P. (2015). Management of Business Informatics Model - Principles and Practices. E\&M Ekonomie a Management, 18(3), 160-173. doi:10.15240/tul/001/2015-3-014.

Watson, R. T., Kelly, G. G., Galliers, R. D., \& Brancheau, J. C. (1997). Key IS Issues in Information Systems Management: An International Perspective. Journal of Management Information Systems, 13(4), 91-115. doi:10.1080/07421222.1997.11518144.

Zhang, S., Zhang, S., Chen, X., \&Huo, X. (2010). Cloud Computing Research and Development Trend. In 2010 Second International Conference on Future Networks (pp. 93-97). Sanya, Hainan, China: IEEE. doi:10.1109/ICFN.2010.58.

doc. Ing. Mgr. Petra Maresova, Ph.D. University of Hradec Kralove Faculty of Informatics and Management petra.maresova@uhk.cz

Ing. Vladimir Sobeslav, Ph.D. University of Hradec Kralove

Faculty of Informatics and Management Vladimir.sobeslav@uhk.cz 


\title{
Abstract
}

\section{EFFECTIVE EVALUATION OF CLOUD COMPUTING INVESTMENT - APPLICATION OF COST BENEFIT METHOD ANALYSIS}

\author{
Petra Marešová, Vladimír Soběslav
}

Use of information and communication technologies both into enterprises and state administration is a great step towards increasing productivity and therefore, economic competitiveness. One of currently ever-spreading technologies is cloud computing. Transfer from the current infrastructure to cloud computing one is risky and expensive matter. The main question when considering cloud computing employment is the investment's effectiveness and return on investment.

The aim of this contribution is to present a model and web application for cloud computing investments evaluation, which will allow customers to answer the main question whether migration from current IT infrastructure to cloud method is suitable or not. The model specifies return on investment based on chosen economic indicators as well as suitability of the solution in regard to characteristics and chosen aspects of company management. Among the main methods used during the model development are multi-criteria variant analysis, quantitative analysis by professional discussions while assembling the model, verification of the initial model with companies, its modification, and application development.

The model is based on Cost Benefit Analysis method, and therefore it allows for considering qualitative variables, by which it significantly differs from the existing web calculators for cloud method cost calculations. Furthermore, the developed application is vendor independent and it is based on the following principles: requirement of inputs that take into account the specifics of companies, scalability and complexity in the form of static and dynamic economic indicators and includes sensitivity analysis and thus enables recalculate the result and based on a certain \% change of input parameters.

Key Words: Investment, cloud computing, cost benefit analysis, calculator.

JEL Classification: M15, M21.

DOI: 10.15240/tul/001/2017-2-010 